\title{
Matérista
}

Revista Matéria, v. 14, n. 1, pp. 680 - 688, 2009

ISSN 1517-7076

http://www.materia.coppe.ufrj.br/sarra/artigos/artigo11003

\section{Análise da pozolanicidade da cinza da casca da castanha do caju pelo método de difratometria de raios $X$}

\author{
Lima, S.A. ; Rossignolo, J.A. ${ }^{\text {II }}$ \\ I Laboratório de Construção Civil - LCC - EESC/USP - Avenida. Trabalhador Sancarlense, 400, 13566-590, \\ São Carlos, SP, Brasil. \\ e-mail: sofiaalima@yahoo.com.br \\ II Escola de Engenharia de São Carlos - EESC/USP, Avenida Trabalhador Sancarlense, 400, 13566-590, São \\ Carlos, SP, Brasil. \\ e-mail: jarossig@sc.usp.br
}

\section{RESUMO}

Atualmente, o aproveitamento de resíduos na construção civil tem sido estimulado, uma vez que esse setor apresenta-se como um dos maiores consumidores de materiais naturais em seus processos e produtos. As cinzas ocupam lugar de destaque entre os resíduos agroindustriais por resultarem de processos de geração de energia. Grande parte dessas cinzas possui atividade pozolânica, podendo ser utilizada como substituto parcial do cimento Portland, resultando numa economia significativa de energia e custo. Este trabalho faz parte de uma pesquisa mais ampla, a qual busca avaliar a viabilidade técnica da cinza da casca da castanha de caju (CCCC) como adição mineral em matrizes de cimento Portland, como também, propor uma metodologia de análise de cinzas agroindustriais. Aplicou-se a técnica de difratometria de raios X para avaliar a reatividade do hidróxido de cálcio pela cinza da casca da castanha de caju em pastas, empregaramse teores de substituição entre 2,5 e 30,0\% e os difratogramas das pastas foram comparados com os das pastas confeccionadas com sílica ativa, executados sobre as mesmas condições de ensaio. Os resultados apontam para a ausência de reatividade pozolânica da CCCC com o cimento Portland.

Palavras-chaves: cinza da casca da castanha de caju, difratometria de raios X, pozolanicidade.

\section{Analysis of pozzolanicity of the rind cashew nut ashes by $\mathrm{X}$-ray diffraction}

\begin{abstract}
Nowadays, the residues exploitation in civil building has been stimulated, mainly because this sector of activity is one of the biggest consumers of natural materials. Some agricultural wastes, such as ashes, have become materials of great interest for building construction because of their pozzolanic activity, and can be used as replacement material for Portland cement, resulting in less energy waste and low cost. This stage of analyses is part of a wider research for the evaluation of the technical viability of the cashew nut rind ashes (CCCC) as mineral admixture in Portland cement products, as well as, the proposition of a methodology of analysis of agroindustrial ashes. In that stage, the technique of X-ray diffraction (XRD) was applied to evaluate the reactivity of the calcium hydroxide for the cashew nut rind ashes in pastes. Substitution rates from 2.5 to $30.0 \%$. The difratograms of the pastes were compared with the ones with silica fume, executed under the same test conditions. The results indicate that the CCCC don't react with the Portland cement.
\end{abstract}

Keywords: cashew nut rind ash, X-ray diffraction, pozzolanicity.

\section{INTRODUÇÃO}

A preocupação com o cenário energético mundial, o qual vem agravando-se desde a crise do petróleo, iniciada em 1973, tem estimulado desde então a busca por fontes de energias renováveis que diminuam o consumo de combustíveis fósseis, esgotáveis e altamente poluentes, por produtos sustentáveis de acordo com as normas ambientais vigentes.

Essas questões têm demandado preocupação dos países desenvolvidos, até então alheios aos apelos da comunidade científica. Perda da diversidade, aumento da temperatura, temporais, diminuição da produção 
de gêneros alimentícios, entre outros problemas, são algumas consequiências do aquecimento global, [1] e que podem frear qualquer tipo de desenvolvimento humano, esteja ele na escala econômica ou social.

Por essa razão, a busca por materiais alternativos, o desenvolvimento de materiais menos poluentes ou que utilizem menos matérias-primas naturais, a reutilização de resíduos sólidos e a diminuição da emissão de gás carbônico são algumas medidas necessárias em vista do atual cenário mundial.

Os subprodutos de origem vegetal, notadamente os subprodutos agroindustriais, resíduos ou cinzas processadas, vêm sendo estudados para utilização como combustíveis, fertilizantes e estabilizantes de solos. A reciclagem desses resíduos é hoje necessária para a preservação do meio ambiente e para a redução do custo e do consumo de energia na produção de materiais e componentes de construção. A construção civil, pelo expressivo volume físico de materiais que incorpora, apresenta grande potencial para utilização desses materiais reciclados [2].

Muitas pesquisas, encontradas na literatura atual, estão sendo desenvolvidas com resíduos agroindustriais para seu aproveitamento como adições minerais em matrizes cimentícias. A utilização de resíduos agroindustriais como adição mineral no cimento Portland tem grande aplicação na construção civil, visto que esses materiais possuem características físicas e químicas que são próprias para utilização em concretos e argamassas [3] . Até o momento, porém, poucas foram as pesquisas desenvolvidas com a cinza da casca da castanha do caju, mesmo que com fins diversos ao da construção civil $[4, \underline{5}]$ e, na bibliografia consultada, inexistem pesquisas sobre o uso da cinza da casca da castanha de caju (CCCC) como adição mineral para concretos e argamassas.

O caju (Figura 1) é formado pelo pedúnculo, pseudofruto carnoso e duro de cor amarela, alaranjada ou vermelha, e pelo fruto verdadeiro do cajueiro, a castanha de caju, de onde se extrai o principal produto de consumo, a amêndoa []].

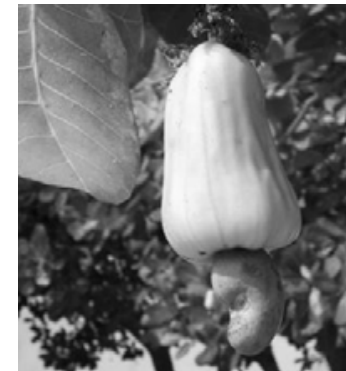

(a)

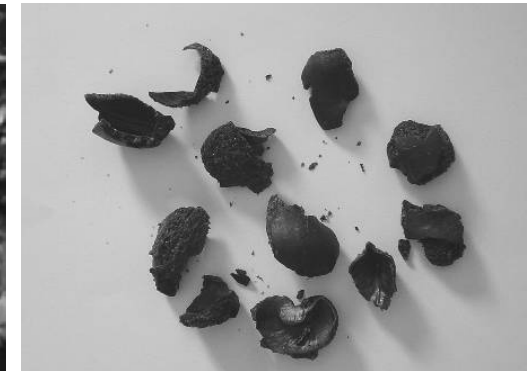

(b)

Figura 1: a) Caju: pedúnculo e castanha. Fonte: Eric Gaba, 2005. Local: Euzébio, CE. b) Cascas de castanhas após decorticação: pedaços não-uniformes

O processo de obtenção da castanha começa pela decorticação, ou seja, a separação da amêndoa e da casca da castanha, o que acontece em tanques com cardol. Esse é aquecido pelo calor gerado em caldeiras ao passar por serpentinas numa temperatura de $800^{\circ} \mathrm{C}$ (variação de $\pm 5^{\circ} \mathrm{C}$ ). Os subprodutos dessa etapa são as amêndoas, de grande valor comercial, e as cascas encharcadas de cardol (Figura 1b), ainda com grande potencial combustível. Comparativamente, o poder calorífico deste resíduo é equivalente ao de outros produtos utilizados para o mesmo fim, como a casca da semente de algodão, a casca de amendoim, a serragem e outros [7]. Essas cascas, resíduos da produção, são incorporadas novamente ao processo e, nas caldeiras, geram calor para decorticação de novas castanhas. A cinza é o resíduo colhido no fundo da grelha das caldeiras, resultante da queima das cascas, cujo resfriamento se faz lentamente. Atualmente, esse resíduo é utilizado como adubo em plantações de caju e uma pequena parte é destinada a aterros sanitários comuns. A cinza representa aproximadamente $5 \%$ do peso da castanha inicial e, com a atual produtividade da cajucultura, a geração dessas cinzas pode chegar a até 15 mil toneladas por ano [8].

Assim, este trabalho tem como objetivo avaliar a viabilidade do uso da CCCC como adição mineral em matrizes cimentícias, utilizando a técnica de difratometria de raios X (DrX). A identificação dos picos presentes no difratograma, por comparação com bancos de dados específicos, permite a avaliação sobre o quanto uma amostra é amorfa ou cristalina, como também, sua comparação, de forma qualitativa, com outros materiais de mesma natureza. Dessa forma, utilizou-se o ensaio de DrX, de forma comparativa, entre pastas moldadas com sílica ativa (SA) e pastas moldadas com cinza da casca da castanha de caju (CCCC). Com esse ensaio, pretende-se analisar a capacidade de fixação do hidróxido de cálcio $(\mathrm{CH})$ residual pela CCCC, comparando seus resultados com os da sílica ativa, adição mineral pozolânica de alta reatividade. Como subsídio à investigação, apresenta-se também a análise química e a análise de pozolanicidade da CCCC. 


\section{MATERIAIS E MÉTODOS}

\subsection{Materiais}

\subsubsection{Cimento Portland}

Utilizou-se o cimento Portland de alta resistência inicial, CPV ARI. As especificações foram fornecidas pelo fabricante, a empresa CIMINAS S.A. - Grupo Holdercim, e encontram-se nas Tabelas 1 e 2.

Tabela 1: Propriedades do CPV ARI

\begin{tabular}{|c|c|c|c|c|}
\hline \multicolumn{3}{|c|}{ Características e propriedades } & Unidade & CPV ARI \\
\hline \multicolumn{3}{|c|}{ Massa específica (NBR 6474) } & $\mathrm{Kg} / \mathrm{dm}^{3}$ & 3,12 \\
\hline \multicolumn{3}{|c|}{ Massa unitária no estado solto (NBR 7251) } & $\mathrm{Kg} / \mathrm{dm}^{3}$ & 1,02 \\
\hline \multirow{3}{*}{ Finura } & Retido \# 20 & (NBR 11579) & $\%$ & 0,20 \\
\hline & Retido \# 32 & & $\%$ & 3,40 \\
\hline & Sup. Esp. $\mathrm{E}$ & laine (NBR 7224) & $\mathrm{cm}^{2} / \mathrm{g}$ & 4687 \\
\hline \multirow{2}{*}{ Tempo de pega } & Iníc & (NBR 11581) & Min & 130 \\
\hline & Fim & $(\mathrm{NBR} 11581)$ & Min & 210 \\
\hline \multirow{4}{*}{\multicolumn{2}{|c|}{$\begin{array}{l}\text { Resistência à compressão }\left(\mathrm{f}_{\mathrm{cj}}\right) \\
\text { (NBR 7215) }\end{array}$}} & 1 dia & $\mathrm{MPa}$ & 27,7 \\
\hline & & 3 dias & $\mathrm{MPa}$ & 42,0 \\
\hline & & 7 dias & $\mathrm{MPa}$ & 46,7 \\
\hline & & 28 dias & $\mathrm{MPa}$ & 56,1 \\
\hline
\end{tabular}

Tabela 2: Composição química do CPV ARI

\begin{tabular}{ccccccccc}
\hline Constituntes & $\mathbf{C a O}$ & $\mathbf{S i O}_{2}$ & $\mathbf{A l}_{2} \mathbf{O}_{3}$ & $\mathbf{F e}_{2} \mathbf{O}_{3}$ & $\mathbf{S O}_{3}$ & $\mathbf{M g O}$ & $\mathbf{K}_{2} \mathbf{O}$ & $\mathbf{P F}^{*}$ \\
Amostra (\%) & 64,03 & 19,65 & 4,99 & 3,17 & 2,56 & 0,83 & 0,69 & 3,61 \\
\hline
\end{tabular}

*PF: perda ao fogo.

\subsubsection{Sílica ativa}

Nesta pesquisa, utilizou-se sílica ativa (SA) proveniente da produção de ferro-silício, comercializada pela Elkem-Microsilica Tecn Ind. e Com. Ltda, com massa específica de 2,21g/ $\mathrm{cm}^{3}$, massa unitária igual a $0,20 \mathrm{~g} / \mathrm{cm}^{3}$, diâmetro médio das partículas de $0,15 \mu \mathrm{m}$ e área específica aproximadamente igual a $20 \mathrm{~m}^{2} / \mathrm{g}$, segundo informações do fabricante. A análise química, apresentada na Tabela 3, foi realizada pelo Centro de Caracterização e Desenvolvimento de Materiais (CCDM) da Universidade Federal de São Carlos (UFSCar).

Tabela 3: Composição química da sílica ativa

\begin{tabular}{ccccccccccc}
\hline Constituntes & $\mathbf{S i O}_{2}$ & $\mathbf{A l}_{2} \mathbf{O}_{3}$ & $\mathbf{F e}_{2} \mathbf{O}_{3}$ & $\mathbf{C a O}$ & $\mathbf{M g O}$ & $\mathbf{K}_{2} \mathbf{O}$ & $\mathbf{P}_{2} \mathbf{O}_{5}$ & $\mathbf{M n O}$ & $\mathbf{T i O}_{2}$ & $\mathbf{P F}^{* *}$ \\
Amostra (\%) & 95,92 & traços & 1,33 & 0,36 & 0,38 & 0,30 & $<\mathrm{LD}^{*}$ & $<\mathrm{LD}^{*}$ & 0,01 & 1,58 \\
\hline
\end{tabular}

*LD: limite de detecção; **PF: perda ao fogo.

\subsubsection{Agregado miúdo}

Foi utilizada a areia normal do IPT, cuja composição granulométrica segue as recomendações da NBR 7214 [9]

\subsubsection{Cinza da casca da castanha de caju}

A cinza utilizada foi cedida pela empresa CIONE - Companhia Industrial de Óleos do Nordeste, localizada em Fortaleza - CE, disposta em sacos lacrados de faces aluminizadas. As amostras utilizadas nesta pesquisa foram coletadas de acordo com os procedimentos previstos na NBR 10007 [10]. A Figura 2 apresenta um difratograma da CCCC in natura. 


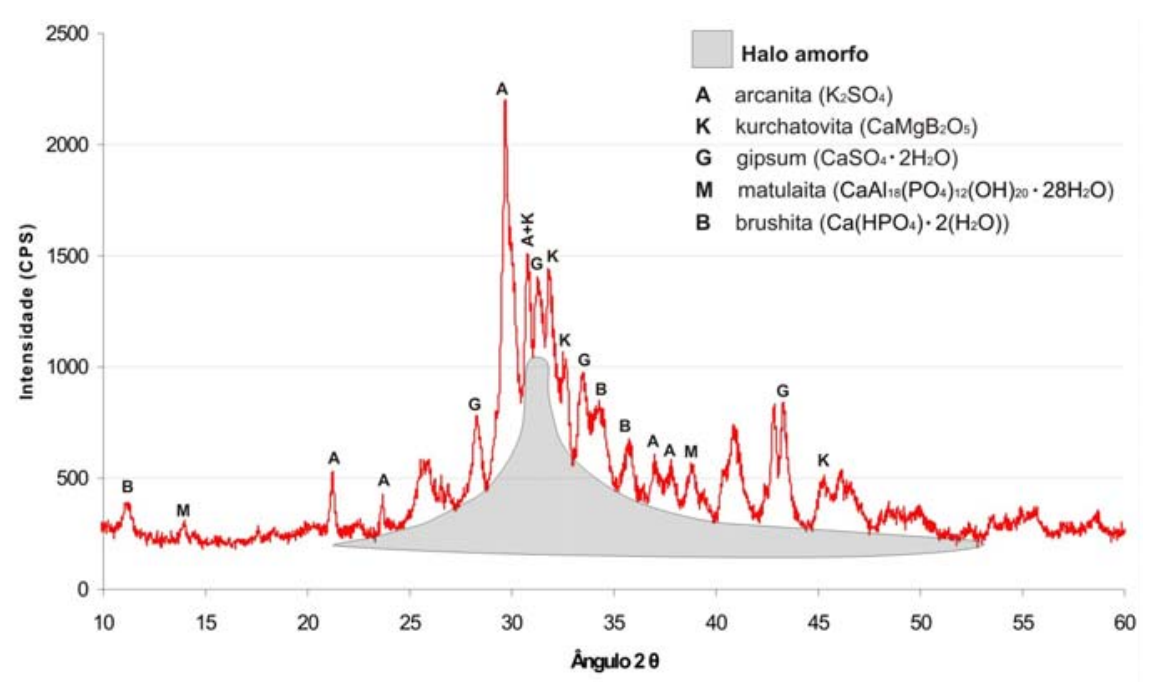

Figura 2: Difratograma da CCCC in natura

\subsection{Métodos}

\subsubsection{Análise química}

A amostra de CCCC foi solubilizada em meio de fusão alcalina e os elementos, determinados em espectrômetro de emissão óptica com plasma induzido, modelo VISTA, da marca Varian, exceto potássio e silício, os quais foram determinados em espectrofotômetro de absorção atômica com chama, modelo Spectra A 640, da marca Varian (IT AQ-158 revisão 009). As análises foram realizadas pelo Centro de Caracterização e Desenvolvimento de Materiais (CCDM) da Universidade Federal de São Carlos (UFSCar).

\subsubsection{Pozolanicidade com o cimento Portland} $5752[\underline{11}]$

Para a análise da pozolanicidade com o cimento Portland, foram utilizados os procedimentos NBR

\subsubsection{Difratometria de raios X (DrX)}

A técnica de difratometria de raios X (DrX) foi utilizada na análise da amostra de CCCC in natura e de 15 pastas, descritas na Tabela 4, com idade de 100 dias. As análises foram realizadas no Laboratório de Cristalografia de Raios X do Instituto de Física de São Carlos da Universidade de São Paulo.

Tabela 4: Dados das pastas para análise por DrX

\begin{tabular}{cc|cc}
\hline Pastas & SA $^{1}(\%)^{3}$ & Pastas & CCCC $^{2}(\%)^{3}$ \\
\hline $1($ Ref $)$ & - & $1($ Ref $)$ & - \\
2 & 2,5 & 9 & 2,5 \\
3 & 5,0 & 10 & 5,0 \\
4 & 7,5 & 11 & 7,5 \\
5 & 10,0 & 12 & 10,0 \\
6 & 15,0 & 13 & 15,0 \\
7 & 20,0 & 14 & 20,0 \\
8 & 30,0 & 15 & 30,0
\end{tabular}

${ }^{1} \mathrm{SA}$ - sílica ativa, ${ }^{2}$ CCCC - cinza da casca da castanha de caju e ${ }^{3}$ porcentagem em relação à massa de cimento Portland.

Utilizou-se um difratômetro de raios X da marca RIGAKU ROTAFLEX, modelo RU200B. As condições para realização das análises foram: radiação: $\mathrm{Cu} \mathrm{K \alpha}$; tensão: $50 \mathrm{kV}$; corrente: $100 \mathrm{~mA}$; varredura com passo de $0,02^{\circ} 2 \theta$; tempo de coleta $2^{\circ} / \mathrm{min}$; intervalo de varredura 3 a $100^{\circ}(2 \theta)$.

Foram utilizados corpos-de-prova cilíndricos de 25 x $50 \mathrm{~mm}$ para a moldagem das pastas. A relação água/aglomerante foi mantida constante para todos os traços, no valor de 0,36. A CCCC utilizada nesse ensaio foi moída durante $1 \mathrm{~h}$ no moinho de bolas e peneirada (material passante na peneira $\mathrm{n}^{\circ} 200$ - abertura 
0,075mm). As características principais do moinho utilizado para a moagem da CCCC são: volume interno de 6,8 litros; velocidade de 132 rotações/minuto; 12 esferas com 170g cada; e quantidade de CCCC utilizada em cada moagem de $700 \mathrm{~g}$.

Após a moldagem, os corpos-de-prova permaneceram em câmara seca com temperatura e umidade controladas (UR $65 \pm 5 \%, 23 \pm 2{ }^{\circ} \mathrm{C}$ ) dentro das formas. Esses foram desmoldados aos 28 dias, permanecendo no mesmo local até o $100^{\circ}$ dia. Ao final desse prazo, os corpos-de-prova foram fragmentados e moídos em almofariz cerâmico. O pó resultante desse processo foi passado na peneira $n^{\circ} 200$ (abertura 0,075mm), sendo coletado o material passante. As amostras foram armazenadas em porta-amostra e submetidas à análise de difratometria de raios $\mathrm{X}$.

\section{RESULTADOS}

Os resultados da análise química da cinza da casca da castanha de caju (CCCC) encontram-se descriminados na Tabela 5, os resultados da análise da pozolanicidade com o cimento Portland são apresentados na Tabela 6 e os resultados obtidos pelo ensaio de difratometria de raios X (DrX) das 15 (quinze) pastas confeccionadas com CCCC e SA encontram-se dispostos na Figura 3.

Tabela 5: Análise química da CCCC

\begin{tabular}{cccccccccccc}
\hline Constituntes & $\mathbf{K}_{2} \mathbf{O}$ & $\mathbf{M g O}$ & $\mathbf{S i O}_{2}$ & $\mathbf{P}_{2} \mathbf{O}_{5}$ & $\mathbf{C a O}$ & $\mathbf{F e}_{2} \mathbf{O}_{3}$ & $\mathbf{N a}_{2} \mathbf{O}$ & $\mathbf{A l}_{2} \mathbf{O}_{3}$ & $\mathbf{M n O}$ & $\mathbf{T i O}_{2}$ & $\mathbf{P F}^{*}$ \\
Amostra (\%) & 24,79 & 16,34 & 12,17 & 10,08 & 6,54 & 3,06 & 2,15 & 1,37 & 0,29 & 0,087 & 17,90 \\
\hline
\end{tabular}

*PF: Perda ao fogo.

Tabela 6: Resultado da análise da pozolanicidade com cimento Portland

\begin{tabular}{ccc}
\hline Propriedade & Amostra PADRÃO & Amostra com CCCC \\
\hline Resistência à compressão (MPa) & 27,2 & 9,3 \\
Índice de Pozolanicidade (\%) & - & 34,3
\end{tabular}

\section{DISCUSSÃO}

\subsection{Análise química}

Para JOHN et al. [12], na avaliação da reatividade de uma adição mineral, é de fundamental importância realizar uma análise química completa, devendo esse material sempre apresentar silício como elemento predominante. Nos resultados da análise química da CCCC (Tabela 5), nota-se um teor de sílica $\left(\mathrm{SiO}_{2}\right)$ no valor de $12,17 \%$, abaixo dos teores recomendados por outras pesquisas [12, $\left.\underline{13}, \underline{14}, \underline{15}\right]$, para que uma cinza apresente reatividade.

Pela análise química, observou-se também a expressiva quantidade de álcalis presentes na CCCC, em maior quantidade de potassa $\left(\mathrm{K}_{2} \mathrm{O}\right), 24,79 \%$, de magnésia $(\mathrm{MgO}), 16,34 \%$, de cálcio $(\mathrm{CaO}), 6,54 \%$, e de sódio $\left(\mathrm{Na}_{2} \mathrm{O}\right), 2,15 \%$. Os álcalis podem prejudicar o desempenho das propriedades do concreto, com destaque para a redução do $\mathrm{pH}$, com consequente despassivação da armadura, e reações expansivas. Além disso, podem influenciar também na velocidade do aumento da resistência desse material [1ㅡ, 17].

O teor de $\mathrm{Na}_{2} \mathrm{O}$, por exemplo, não pode ultrapassar 0,6\% em massa no concreto. A NBR 12653 [18] também limita a quantidade de equivalentes de $\mathrm{Na}_{2} \mathrm{O}$ nos materiais pozolânicos em 1,5\%. O cálculo da equivalência de $\mathrm{Na}_{2} \mathrm{O}$ leva em consideração também o teor de potássio através da equação " $\mathrm{Na}_{2} \mathrm{O}+$ $0,64 \mathrm{~K}_{2} \mathrm{O}$ ” [16]. Por essa fórmula, a quantidade de álcalis disponíveis na CCCC fica em 18,02\%, indicando seu uso em baixos teores. Esses teores dependerão da composição química do cimento Portland utilizado.

\subsection{Pozolanicidade}

O resultado da análise da pozolanicidade com o cimento Portland, apresentado na Tabela 6, indica que o índice de pozolanicidade (IP) dos corpos-de-prova com CCCC foi de 34,3\%, bem abaixo do valor exigido pela NBR 5752 [11] e pela NBR 12653 [18], de 75,0\%. Dessa forma, a CCCC não se enquadra nos parâmetros mínimos exigidos pela NBR 5752, não sendo classificada como material pozolânico.

$\mathrm{O}$ baixo IP pode ser atribuído essencialmente à baixa quantidade de materiais potencialmente reativos presentes na CCCC, sendo eles $\mathrm{SiO}_{2}, \mathrm{Al}_{2} \mathrm{O}_{3}$ e $\mathrm{CaO}$, que somados representam 20,08\% da composição dessa cinza. A recomendação da NBR 12653 [18] para materiais pozolânicas é de que esse teor 
seja no mímino de 50\%. Ressalta-se que a sílica ativa utilizada nesta pesquisa apresenta o teor de aproximadamente 96\% de materiais potencialmente reativos (Tabela 3).
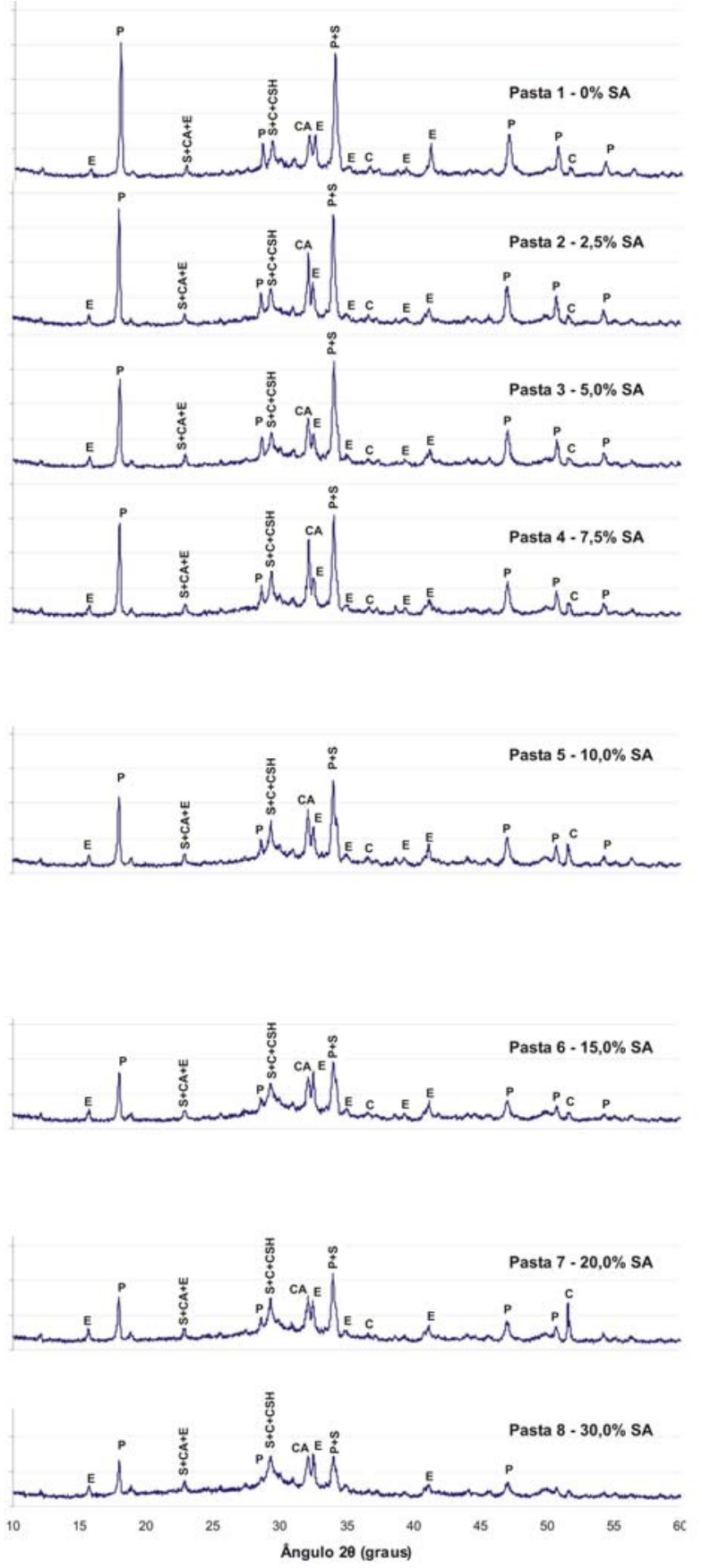

P: portlandita (Hidróxido de cálcio - $\mathrm{CH}$ )

$\left(\mathrm{Ca}(\mathrm{OH})_{2}\right)$;

C: calcita $(\mathrm{CaO})$;

CA: carboaluminato $\left(3 \mathrm{CaO} \cdot \mathrm{Al}_{2} \mathrm{O}_{3} \cdot \mathrm{CaCO}_{3} \cdot\right.$ $\left.12 \mathrm{H}_{2} \mathrm{O}\right)$

E: etringita $\left(3 \mathrm{CaO} \cdot \mathrm{Al}_{2} \mathrm{O}_{3} \cdot 3 \mathrm{CaSO}_{4}\right.$.

$\left.31 \mathrm{H}_{2} \mathrm{O}\right)$;

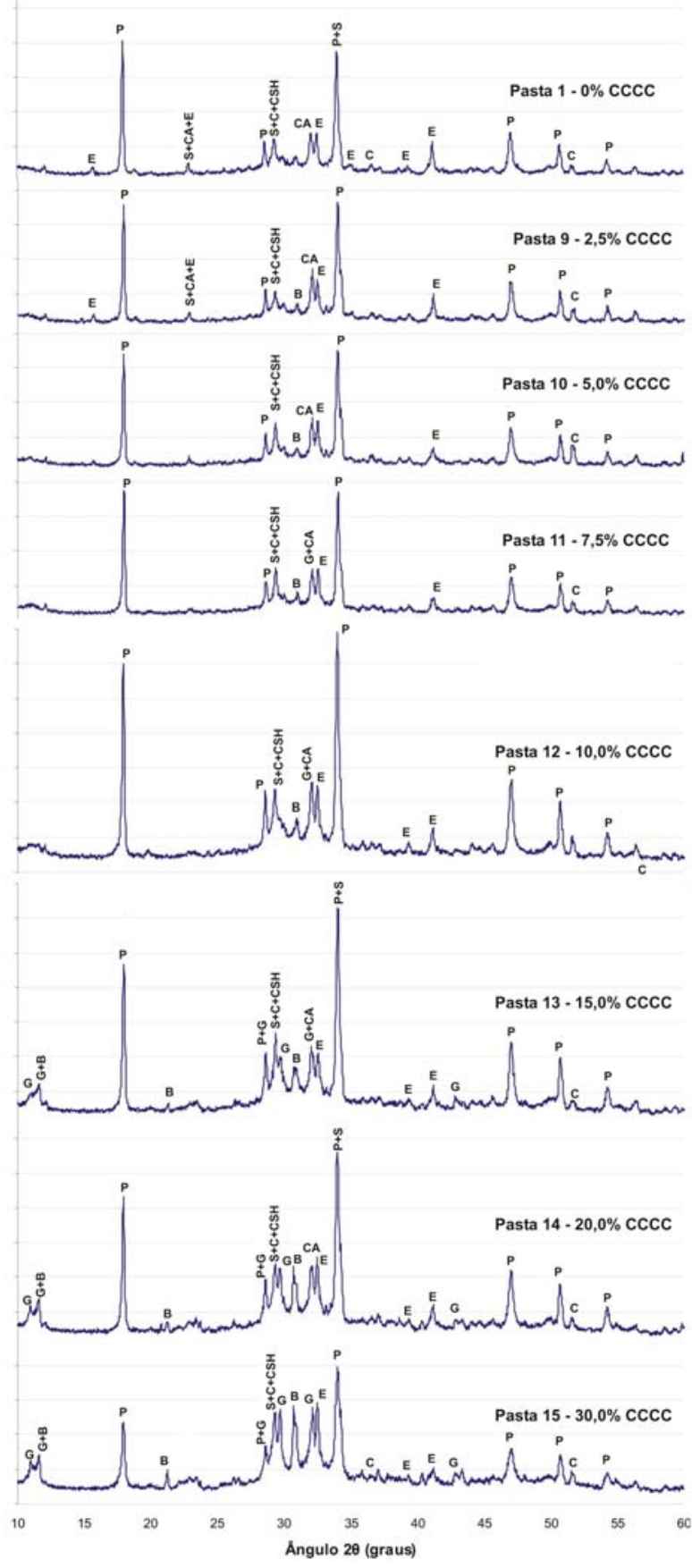

S: silicato de cálcio anidro (alita e belita).

B: bruchita $\left(\mathrm{CaPO}_{3}(\mathrm{OH}) \cdot 2 \mathrm{H}_{2} \mathrm{O}\right)$;

G: gorgeita $\left(\mathrm{K}_{2} \mathrm{Ca}_{5}\left(\mathrm{SO}_{4}\right) \cdot 6 \mathrm{H}_{2} \mathrm{O}\right)$

CSH: silicato de cálcio hidratado $\left(\mathrm{C}_{9} \mathrm{~S}_{6} \mathrm{H}_{11}\right)$ (C-S-H I)

Figura 3: Difratogramas das pastas moldadas com SA e com CCCC 


\subsection{Difratometria de raios $X$}

A principal fase cristalina hidratada do cimento Portland detectada nas pastas analisadas por este método foi o hidróxido de cálcio $(\mathrm{CH})$, identificado por seis picos, sendo o de maior intensidade em $2 \theta=34,1^{\circ}(\mathrm{d}=2,63 \AA)$. A banda difusa do silicato de cálcio hidratado (C-S-H) pode ser identificada na elevação da linha base entre $28^{\circ}$ e $36^{\circ}(2 \theta)$, com pico de referência (C-S-H I) em $2 \theta=28,7^{\circ}(d=3,11 \AA)$. Foram identificados ainda picos pertencentes à alita e à belita (principais fases do clínquer), indicando que a hidratação do cimento não se deu de forma completa, como o esperado.

Todas as pastas analisadas apresentaram picos pertencentes à etringita (E), à calcita $(C)$ e ao carboaluminato (CA). No entanto, apenas nas pastas com CCCC foi observada a tendência de aumento dos picos dessas fases com o aumento da adição da cinza. A presença de sulfatos na CCCC, constatado no difratograma da cinza in natura (Figura 2) nos elementos arcanita (A) e gesso (G), pode estar favorecendo o aumento de etringita nas pastas. Já o aumento de intensidade dos picos das fases calcita e carboaluminato pode ter sido ocasionado pela presença de cálcio e alumínio na CCCC, observado na análise química (Tabela 5) e no difratograma da cinza in natura (Figura 2)

Observou-se, também, nas pastas com teores de CCCC acima de 15\%, o aparecimento de picos referentes aos minerais gorgeita $\left(\mathrm{K}_{2} \mathrm{Ca}_{5}\left(\mathrm{SO}_{4}\right) \cdot 6 \mathrm{H}_{2} \mathrm{O}\right)$ e bruchita $\left(\mathrm{CaPO}_{3}(\mathrm{OH}) \cdot 2 \mathrm{H}_{2} \mathrm{O}\right)$, evidenciados nos difratogramas das pastas 13, 14 e 15 (Figura 3). Esses minerais são formados, respectivamente, pelas espécies químicas potássio e fósforo, que são dois dos principais constituintes da CCCC. Não foram encontrados, na bibliografia consultada [12, $\underline{15}, \underline{16}, \underline{17}, \underline{19}]$, estudos sobre a influência desses compostos em matrizes cimentícias.

A análise da evolução da fase cristalina do $\mathrm{CH}$, em função da adição de sílica ativa (SA) e de cinza da casca da castanha de caju (CCCC), foi realizada por meio da análise da relação entre o pico de maior intensidade dessa fase, em $2 \theta=34,1^{\circ}(\mathrm{d}=2,63 \AA)\left(\mathrm{I}_{\mathrm{CH} 34,1^{\circ}}\right)$, e o pico de C-S-H I em $2 \theta=28,7^{\circ}\left(\mathrm{I}_{\mathrm{CSH} 28,7^{\circ}}\right)$, conforme ilustrado na Figura 4. Apesar do C-S-H I apresentar baixa cristalinidade, pode ser usado como referência para análise relativa das demais fases cristalinas nas pastas hidratadas de cimento Portland [19, 20].

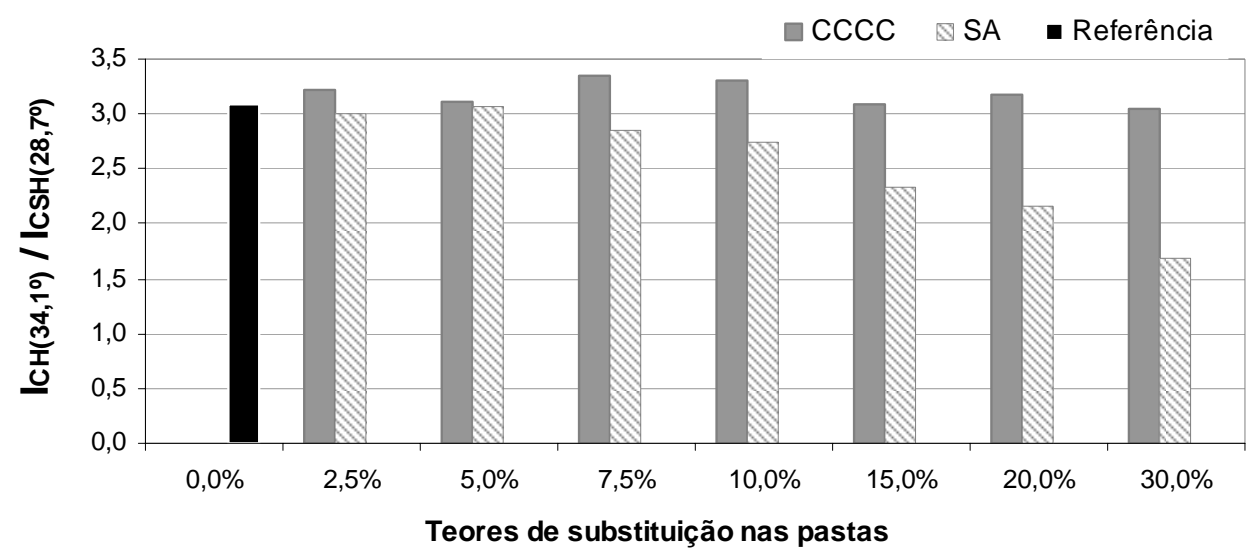

Figura 4: Valores da relação entre as intensidades dos picos de $\mathrm{CH}$, em $2 \theta=34,1^{\circ}\left(\mathrm{I}_{\mathrm{CH} 34,1^{\circ}}\right)$, e de C-S-H I, em $2 \theta=28,7^{\circ}\left(\mathrm{I}_{\mathrm{CSH} 28,7^{\circ}}\right)$.

Na Figura 4, observa-se que a adição de SA nas pastas reduziu o valor da relação entre os picos de CH e C-S-H I de forma significativa em relação ao obtido para a pasta de referência, chegando à redução de $45 \%$ do valor dessa relação para a pasta com 30\% de adição. Esse resultado, que era esperado, evidencia o potencial pozolânico da sílica ativa, oqual pode ser observado, também, nos difratogramas das pastas com SA na Figura 2, onde se verifica a redução da intensidade do pico de $\mathrm{CH}$ com o aumento da adição mineral. Essa redução da intensidade do pico indica a reação do CH com a SA resultando em C-S-H [19 $\underline{19}$ 20, 21] .

Já nas pastas com adição de CCCC não houve redução da relação entre os picos de CH e C-S-H I para níveis inferiores ao obtido na pasta de referência (Figura 4). Esse fato, que também pode ser observado na intensidade dos picos de $\mathrm{CH}$ nas pastas com CCCC (Figura 3), indica que essa cinza não apresentou efetividade na reação com o CH, ou seja, a adição de CCCC, nos teores estudados, não alterou a quantidade de CH em relação ao C-S-H I nas pastas, indicando que não houve reação pozolânica. Esse resultado está em conformidade com a análise de pozolanicidade da CCCC (item 4.2), isto é, indica a ausência da pozolanicidade dessa cinza, que, como mencionado anteriormente, pode ser atribuído essencialmente à baixa quantidade de materiais potencialmente reativos $\left(\mathrm{SiO}_{2}, \mathrm{Al}_{2} \mathrm{O}_{3}\right.$ e $\left.\mathrm{CaO}\right)$. 


\section{CONCLUSÕES}

Na análise dos difratogramas das pastas estudadas, pode-se observar a ausência de reatividade da CCCC com o hidróxido de cálcio $(\mathrm{CH})$, indicando assim que essa cinza não apresenta potencial pozolânico.

Contribuem para esse resultado, a análise química da CCCC, que apresentou baixos teores de materiais pozolânicos potencialmente reativos, e a análise da pozolanicidade com o cimento Portland, no qual a CCCC não foi classificada como material pozolânico.

Além disso, verificou-se que a adição de CCCC favorece a formação de etringita, de calcita e de carboaluminatos. Especialmente em pastas com teores de CCCC acima de 15\%, observou-se a formação dos minerais gorgeita e bruchita.

\section{AGRADECIMENTOS}

À Fundação de Amparo à Pesquisa do Estado de São Paulo - FAPESP, pelo apoio financeiro e ao Laboratório de Construção Civil - LCC da Escola de Engenharia de São Carlos, USP, pelo suporte na realização das análises.

\section{REREFÊNCIAS}

[1] GREENPEACE, http://www.greenpeace.org.br/clima/pdf/convencao onu.pdf. Acessado em fevereiro de 2007.

[2] SILVA, M.G., SOUZA, F.L.S., "Proposta de utilização de resíduos da indústria de celulose e papel e entulho de obra em componentes de construção", In: anais do VI Encontro de Tecnologia no Ambiente Construído, v. 2, pp. 749-754, Rio de Janeiro, Outubro 1995.

[3] MANNAN, M.A., GANAPATHY, C., "Concrete from an agricultural waste oil-palm shell (OPS)", Building \& Environment, v. 39, n. 4, pp. 441-448, Abril 2004.

[4] ALMEIDA, F.A.G., FONTES, J.M., ALMEIDA, F.C.G., "Uso da cinza da casca de castanha de caju, Anacardium occidentale L., como fonte de fósforo para a cultura do milho", Revista de Ciência Agronômica, v. 19, n. 1, pp. 73-78, Junho, 1988.

[5] SILVA, A.C., LIMA, S.A., LEITE, R.C.V., PAULA, F.S., SOARES, R.N., "Análise da viabilidade técnica do resíduo da castanha do caju em tijolos do adobe", In: anais do IV Encontro de Iniciação Científica e Tecnológica - ENICIT, v. 1, pp. 49, Fortaleza, CE, Agosto, 2004.

[6] PAIVA, F.F.A., GARRUTTI, D.S., SILVA NETO, R.M., Aproveitamento industrial do caju, 1 ed., Ceará, SEBRAE, 2000.

[7] SILVA, A.C., LIMA, S.A., LEITE, R.C.V., et al, "Utilização do resíduo da castanha do caju na confecção de tijolos de terra crua (adobe): alternativas para redução do custo final de moradias de interesse social no Brasil”, In: anais do X Encontro de Geógrafos da América Latina - EGAL, v. 1, CD-ROM, São Paulo, SP, 2005.

[8] LIMA, S.A., ROSSIGNOLO, J.A., "Análise preliminar da viabilidade do uso da cinza da casca da castanha de caju em produtos para construção civil”, In: anais do VIII Seminário Desenvolvimento Sustentável e a Reciclagem na Construção Civil, v. 1, CD-ROM, Bento Gonçalves, RS, Setembro, 2007.

[9] ASSOCIAÇÃO BRASILEIRA DE NORMAS TÉCNICAS - ABNT, NBR 7214 - Areia normal para ensaio de cimento - Especificação, Rio de Janeiro, 1982.

[10] ASSOCIAÇÃO BRASILEIRA DE NORMAS TÉCNICAS - ABNT, NBR 10007 - Amostragem de resíduos sólidos, Rio de Janeiro, 2004.

[11] ASSOCIAÇÃO BRASILEIRA DE NORMAS TÉCNICAS - ABNT, NBR 5752 - Materiais Pozolânicos - Determinação da atividade pozolânica com cimento Portland - índice de atividade pozolânica com cimento, Rio de Janeiro, 1992. 
[12] JOHN, V.M., CINCOTTO, M.A., SILVA, M.G., “Cinzas e aglomerantes alternativos”, In: Freire, W.J., Beraldo, A.L. (eds), Tecnologias e Materiais Alternativos de Construção, 1 ed., capítulo 6, pp. 145190. Campinas, SP, Editora da UNICAMP, 2003.

[13] CINCOTTO, M.A., KAUPATEZ, R.Z., "Seleção de materiais quanto à atividade pozolânica”, In: IPT Tecnologia de Edificações, 1 ed, capítulo 3, São Paulo, Editora Pini, 1988.

[14] PRUDÊNCIO JR, L.R., SANTOS, S., DAFICO, D.A., “Cinza da casca de arroz”, In: Rocha, J.C., John, V.M. (eds), Utilização de Resíduos na Construção Habitacional, 1 ed, Coleção Habitare, v. 4, capítulo 8, Porto Alegre, ANTAC, 2003.

[15] CINCOTTO, M.A., “Utilização de subprodutos e resíduos na indústria da construção civil”, In: IPT, Tecnologia de Edificações, 1 ed, capítulo 5, São Paulo, Editora Pini, 1988.

[16] MEHTA, P.K., MONTEIRO, P.J.M., Concreto - estrutura, propriedades, materiais, 1 ed., vol. 1, São Paulo, PINI, 1994.

[17] NEVILLE, A.M., Propriedades do concreto, 1 ed., São Paulo, PINI, 1997.

[18] ASSOCIAÇÃO BRASILEIRA DE NORMAS TÉCNICAS - ABNT, NBR 12653 - Materiais Pozolânicos, Rio de Janeiro, 1992.

[19] LEA, F.M., The chemistry of cement and concrete, 3 ed., New York, Chemical Publishing Company Co, 1971.

[20] CHATTERJEE, A.K., “X-Ray diffraction”, In: Ramachandran, V.S., Beaudoin, J.J. (eds), Handbook of analytical techniques in concrete science and technology: principles, techniques, and applications, 1 ed., chapter 8, USA, Noyes Publications, 2001.

[21] NITA, C., JOHN, V.M., "Materiais pozolânicos: o metacaulim e a sílica ativa”, BT/PCC/451, Série Boletim Técnico da Escola Politécnica da USP, Departamento de Engenharia de Construção Civil. v. 1, pp. 13, São Paulo, EPUSP, 2007. 